Research Journal of Applied Sciences, Engineering and Technology 16(1): 30-42, 2019

DOI: $10.19026 /$ rjaset.16.5996

ISSN: 2040-7459; e-ISSN: 2040-7467

(C) 2019 Maxwell Scientific Publication Corp.

Submitted: October 18, 2018

Accepted: December 16, 2018

Published: January 15, 2019

\title{
Research Article \\ Implementing the System, Instructor and Student Model to Achieve Required Software Quality Assurance
}

\author{
${ }^{1}$ Fatima M.H. Amin, ${ }^{2}$ Nadir K. Salih and ${ }^{1}$ AwadElkarim Mohammed \\ ${ }^{1}$ Faculty of Information Technology, Al-Neelain University, \\ ${ }^{2}$ Department of Electrical and Computer Engineering, Engineering College, Karary University, Sudan
}

\begin{abstract}
This study implements the System, Instructor and Student Model to achieve required software quality assurance. A software application was developed considering the factors of System, Instructor and Student Model. ASP.NET is used for building the application along with C\# programming language. The graphical user interface was built using HTML5. The application was tested over three educational institutions in Sudan. The obtained results were compared to determine if they are really satisfying the requirements, needs and acquisition of the right knowledge according to quality assurance. The model has easily corrected the mistakes in the previous models and addressed the defects that occurred. The results were accurate and promising. We hope that this model serves as a basis for the evaluation of other E-learning softwares in the future.
\end{abstract}

Keywords: E-Learning, quality, SISM model, software, software application, software quality assurance

\section{INTRODUCTION}

Software can be defined as all or part of programs, procedures, rules and associated documentation of an information processing system. Thus, programs are only one part of a set of other components (April and Laporte, 2018). Software quality is confirmed to determine software needs, the potential of a software to satisfy needs when used under specified conditions (ISO 2500[ISO 11i]) or the degree to which a software product meets established requirements. Quality depends upon the degree to which those established requirements accurately represent stakeholder needs, wants and expectations (April and Laporte, 2018).

Quality assurance is the systematic way to check whether the product and services are meeting the specified requirements and standards, achieving the desired level of customer satisfaction. It increases the customer confidence, satisfaction, credibility of the product and enable the product to compete with other products in the market (Mateen and Sirshar, 2015).

Software Quality Assurance (SQA) refers to effective and continuous quality validations and verifications within the software development life cycle to ensure the fitness for purpose, conformance to specifications and that the end product meets the needs of the customer (Koka, 2015).

E- Learning is an application of information technology used in education. It has brought a lot of positive impacts to human life in education and brought much benefit (Rohayani et al., 2015). It is a formalized teaching and learning system specifically designed to be carried out remotely by using electronic communication. Distance learning is situations where traditional education has difficulty in operating. Students with scheduling or distance problems can benefit, as well as employees, because distance education can be more flexible in terms of time and can be delivered virtually anywhere. E-learning is an opportunity to explore the place of distance learning in a wider world where cultures and ideologies clash, where education and employment are no longer stable and secure, where universities and colleges are under unprecedented pressures, where the technologies and trends of education technology represent a crowded and chaotic space and where a critical examination of distance learning is necessary to underpin its methods and its mission (Traxler, 2018). Enterprises, companies and educational institutions always want to satisfy their customer needs and meet their requirements while taking into consideration the necessary profit. For educational institutions, the outlook is different because you must do it in correct way to grab the student's attention. Therefore, it must be done efficiently by using technologies to help students to get the right knowledge and useful education and suitable technology to deliver his/her subjects effectively. Improving student engagements enhances learning motivation because student feels that he/she got the meaningful subject materials which support their 
confidence. The subjects must be clear, specific and include their ambitions. When the information is timely updated, presented in an easy way and using suitable multimedia all these help in the motivation the Elearning. In the last decade, the quality model became the most important thing in building integrated software application. Thus, organizations do not rely on a single quality model to achieve desired student and instructor needs and requirements.

E-Learning readiness involves many components of E-learning, including students, lectures, technology and environment, which must be ready in order to formulate a coherent and achievable strategy (Mosa et al., 2016). There is a lack of a standard methodology that can be used to evaluate the effectiveness of different E-learning applications due to their diversity and complexity (Hammad et al., 2015).

The quality model is a mean to specify and evaluate the quality specifications of software. In 1977, Jim McCall presented the first quality model towards the system developers and the system development process. McCall attempts to establish a link between users and developers by defining a number of software quality factors that reflect both user views and the developer's priorities. Another model is Boehm's model that attempts to qualitatively define software quality by a given set of attributes and metrics. Boehm's model presents a hierarchical quality model structured around high-level characteristics, intermediate level characteristics and primitive characteristic. R. Geoff Dromey, a more recent quality model, is based on the relationship between quality attributes and subattributes as well as the connection between the product properties and software quality attributes (Djouab and Bari, 2016).

The model is the important part of any software product. The use of models is an acceptable means to support quality management software products (Miguel et al., 2014). There is a great difference between the quality evaluation models. The evaluation process is difficult and depends on the goals that the product is responsible for such as customer or student requirements, so as to satisfy their needs, to get high globalization society education, to get low technologies cost, to be effective in quality of E-learning services and competition in quality E-learning services.

If there is another model that does the same job it would be easy to evaluate the new one by comparing the results with the old one. Usage of software application for the target model to evaluate E-learning software is what we used to proof our quality model. The evaluation process examines the E-learning software effectiveness that points of defects which are not known clearly and all aspects of the model. The System, Instructor and Student Model (SISM) model (Amin and Salih, 2017) which we aim to evaluate its quality with respect to other models in E-learning, has three sides system, student and instructor sides. There is an intersection between the three sides which increases the effectiveness and efficiency of the model (Amin and Salih, 2017).

Our aim is to implement the SISM model by designing a software application to achieve acceptable level of quality.

\section{LITERATURE REVIEW}

There are numerous research articles which talk about the models evaluation for different products. The model is the key success for any product to fulfill the software quality assurance aspect.

Early on 2012, questionnaires were used to evaluate quality models and measuring dimensions were extracted and used as a benchmark. (Zhang and Cheng, 2012). Tools were used to analyze the characteristic features of the software models (Storch et al., 2013). Quality and quantity dimensions were considered to optimize system performance (Trichkova, 2014). Aspects of communications play an important factor in the quality of software (Miguel et al., 2014). Custom softwares demands combining different elearning models for evaluation (Hammad et al., 2015). Metrics products from ISO/IEC9126 were used to develop and improve a model to aid the government to business (G2B) model (Andrian et al., 2016). The latter model was further extended with the specific characteristics of the E-learning software product and integrating them in the ISO 2126 model (Djouab and Bari, 2016). Emergence of IoT applications proposed a new quality model (Kim, 2016). Technological readiness dictates e-learning readiness (Mosa et al., 2016). Recently, a formal software architecture of quality management framework for e-learning was constructed to control the quality of the E-learning process and assure institutions regulations and policies (Allehaibi and Albaqami, 2017).

\section{MATERIALS AND METHODS}

The instrumentation aims at utilizing the common web technologies to provide user friendly software. With the explosive increase of information services using World Wide Web (WWW), the practical application of web-based systems is considerable. HTML5 remains the basic language for building webpages due to its robustness. Active Server Page (ASP) is a marvelous technology for building web applications especially when integrated with.NET framework offered by Microsoft. It includes large number of classes for web development and deployment. The C\# language is intended to be a simple, modern, generalpurpose, object-oriented programming language. $\mathrm{C \#}$ is intended to be suitable for writing applications for both hosted and embedded systems. Here, we used an online web application which we developed using HTML5, ASP.NET and C\#. 
The SISM software quality models have two factors:

- Design factors

- Implementation factors

Each of which has its own factors that help to complete its job and to satisfy the customer needs and requirements. For simplicity, the factors are given a score of ten. A score greater than eight is remarkably significant, while a score ranging from five to eight is acceptable. A score less than five is considered non satisfactory.

The data for implementing the SISM model evaluation were collected from two universities and one school, the universities are A, B and the school is C. Meetings were arranged to collect the data and analyze the existing E-learning software.

SISM model design factors were divided into student side, instructor side and system side.

Student side: Student side operations are performed when student visits the E-Learning system through the browser to get information, to solve a problem/exercise, to see lectures, textbooks and all data sent by the instructors.

Usability relies mainly on the general interface design, whether or not documentation is included and the ease of use. Ease of use can be analyzed based upon simplicity, clarity, colors and contents. As shown in Table 1, the general design interface is given the highest score. Within the ease of use, clarity and contents have greater scores. Recent research suggests that the aesthetics of an interface can have a positive effect on people's perception of the system's usability (Preece et al., 2015)

Learnability assesses how easily a student can gain knowledge in the shortest time and the least cost (Sons, 2002). It relies mainly on the display/layout of the contents, the fonts and the images used. As shown in Table 2, the display/layout comprises a considerable proportion (Pausch et al., 1992).

Understandability assesses how clear the information which the instructors wrote is. It relies mainly on the consistency, grammar and spelling (Amin and Salih, 2017) as shown in Table 3. It is important to devise the interface on paper first and paying attention to the clarity and consistency of the objects, layout and so on (Preece et al., 2015).

Instructor side: Instructor side operations play a central role in the effectiveness and success of ELearning based courses.

Reliability aims to measure the ability of the system to keep operating for a long time without developing failure. In other words, it is the ability to perform the promised service dependably and accurately (Amin and Salih, 2017). It is how well it
Table 1: Usability factors

\begin{tabular}{ll}
\hline Factors & Score $(/ 10)$ \\
\hline General design interface & 4 \\
Documentation & 3 \\
Ease of use & \\
Simplicity & 0.6 \\
Clarity & 0.9 \\
Colors & 0.6 \\
Contents & 0.9 \\
\hline
\end{tabular}

Table 2: Learnability factors

\begin{tabular}{ll}
\hline Factors & Score $(/ 10)$ \\
\hline Display/Layout & 6 \\
Font & 3 \\
Images & 1 \\
\hline
\end{tabular}

Table 3: Understandability factors

\begin{tabular}{ll}
\hline Factors & Score $(/ 10)$ \\
\hline Consistency & 5 \\
Grammar & 3 \\
Spelling & 2 \\
\hline
\end{tabular}

Table 4: Reliability factors

\begin{tabular}{ll}
\hline Factors & Score $(/ 10)$ \\
Performance & \\
Server speed & 1.98 \\
Number of users & 1.98 \\
Bandwidth & 1.98 \\
Error rate & 4 \\
\hline
\end{tabular}

Error rate

Table 5: Testability factors

\begin{tabular}{ll}
\hline Factors & Score $(/ 10)$ \\
\hline Log files & 3 \\
Notifications (Errors/Warnings) & 4 \\
Dashboard & 3 \\
\hline
\end{tabular}

produces the same results on separate occasions under the same circumstances (Preece et al., 2015). It relies on performance and error rate, as shown in Table 4. Performance is assessed upon server speed, number of users associated and the network bandwidth with even scores. Error rate is given a score less than performance.

Correctness measures extent to which a program satisfies its specifications and fulfills the student's mission objectives (Amin and Salih, 2017). These specifications vary according to the user needs. It is an evaluative measure.

System side: System side play fundamental role in Elearning. The most attractive feature of E-Learning according to student and instructor both is its flexibility of location and time.

Testability is related to special features in the program that help the tester to detect defects as soon as they are introduced. Thus, reducing the cost and time to fix the bug. It depends upon whether or not log files are included, errors/warnings notifications and dashboard (Amin and Salih, 2017). An interface that allows the users to interact with the messages would be very useful (Preece et al., 2015). Therefore, notifications are an essential testability feature (Table 5).

Flexibility measures the ease with which a system or component can be modified for use in applications or 
Res. J. Appl. Sci. Eng. Technol., 16(1): 30-42, 2019

Table 6: Flexibility factors

\begin{tabular}{ll}
\hline Factors & Score $(/ 10)$ \\
\hline Database & 6 \\
Programming & 4 \\
\hline
\end{tabular}

Table 7: Portability factors

\begin{tabular}{ll}
\hline Factors & Score $(/ 10)$ \\
\hline Plug and play & 10 \\
\hline
\end{tabular}

Table 8: Effectiveness factors

\begin{tabular}{ll}
\hline Factors & Score $(/ 10)$ \\
\hline $0-30$ seconds & 10 \\
$31-60$ seconds & 6 \\
$61-90$ seconds & 3 \\
$91-$ above seconds & 1 \\
\hline
\end{tabular}

Table 9: Reusability factors

\begin{tabular}{ll}
\hline Factors & Score $(/ 10)$ \\
\hline Webpages & 7 \\
Objects/modules/DLL & 3 \\
\hline
\end{tabular}

Table 10: Maintainability factors

\begin{tabular}{ll}
\hline Factors & Score $(/ 10)$ \\
\hline Admin panel & 10 \\
\hline
\end{tabular}

environments other than those for which it was specifically designed (Amin and Salih, 2017). It relies on the software architecture. Nowadays, databases play a crucial role in modifying system components easily (Lakshmanan et al., 1997, Levandoski et al., 2013, Preece et al., 2015) (Table 6).

Functionality measures the attributes that satisfy the needs of the user. These features range from online support, responsive designs, control panels, video support, mobile support, backup and recovery, atomicity, cross platform, etc. These are evaluative.

Portability measures migration of component from one system to another with little or no modifications (Amin and Salih, 2017). Plug and play is the standard measure here, as shown in Table 7. Recently schools and universities have realized the potential of using combinations of technologies to support learning. (Sons, 2002).

Effectiveness is the ability to perform our tasks quickly and proficiently. It is measured by the software's correctness and the accuracy achieved while performing specific goals. This can be achieved by taking the maximum time needed to perform the task and comparing it with a scale from 0-91 sec. Scores are provided accordingly, as shown in Table 8 .

Re-usability deals with the use of software modules originally designed for one project in a new software project currently being developed, as shown in Table 9. Nowadays, this can be achieved through object oriented programming, DLL files, modules, webpages, etc.

Maintainability measures the effort needed to make specified modifications. Nowadays, admin panels play a crucial role in modifications, as shown in Table 10.

Navigability deals with the ease of student's quick and efficient access to the content and ease for them to get the knowledge, lectures, exercise and subjects
Table 11: Navigability factors

\begin{tabular}{ll}
\hline Factors & Score $(/ 10)$ \\
\hline 1 click & 10 \\
2 clicks & 8 \\
3 clicks & 6 \\
4 clicks & 4 \\
5 clicks & 2 \\
More than 5 clicks & 1 \\
\hline
\end{tabular}

Table 12: Privacy factors

\begin{tabular}{ll}
\hline Factors & Score $(/ 10)$ \\
\hline Security updates & $0-10$ \\
\hline & \\
Table 13: Interoperability factors & \\
\hline Factors & Score $(/ 10)$ \\
\hline Data migration & $0-5$ \\
System migration & $0-5$ \\
\hline
\end{tabular}

related to their study. Less number of clicks needed to accomplish a certain operation is satisfactory. Therefore, the maximum number of clicks needed is compared to a scale of one to five clicks and the scores are provided accordingly (Jiménez Iglesias et al., 2018) as shown in Table 11.

Intersections side: Intersections side comprises the common elements within system, student and instructor sides.

Security refers to how the software is able to control the unauthorized access to the services it provides. It is assessed by many factors such as user authentication, SSL, DDOS, IDS, cookies and sessions, etc. It is an evaluative measure.

Efficiency is the ability of the software product to provide high level of performance with the least amount of resources. It relies on the software architecture mainly and is an evaluative measure.

Integrity requires that data and processes are protected from unauthorized modification. It relies on data security (encryption, system authorization), SSL, DDOS, cookies and sessions. It is an evaluative measure.

Privacy is how secure data is to be maintained across all systems. Security updates are important measure here (Table 12).

Interoperability is how easy system can exchange data or services with other systems. It relies on data and system migration, as shown in Table 13.

Once the software application is developed, the elearning software assessment process starts by collecting the required data for each factor. The data is then entered in our software application for evaluation and the results are obtained for each design factor. Finally, a summary report for the e-learning software is displayed.

Organization A: Organization A is an undergraduate and postgraduate institution that provides diploma, bachelor, masters and doctorate degrees for students. It 


\section{System Side}

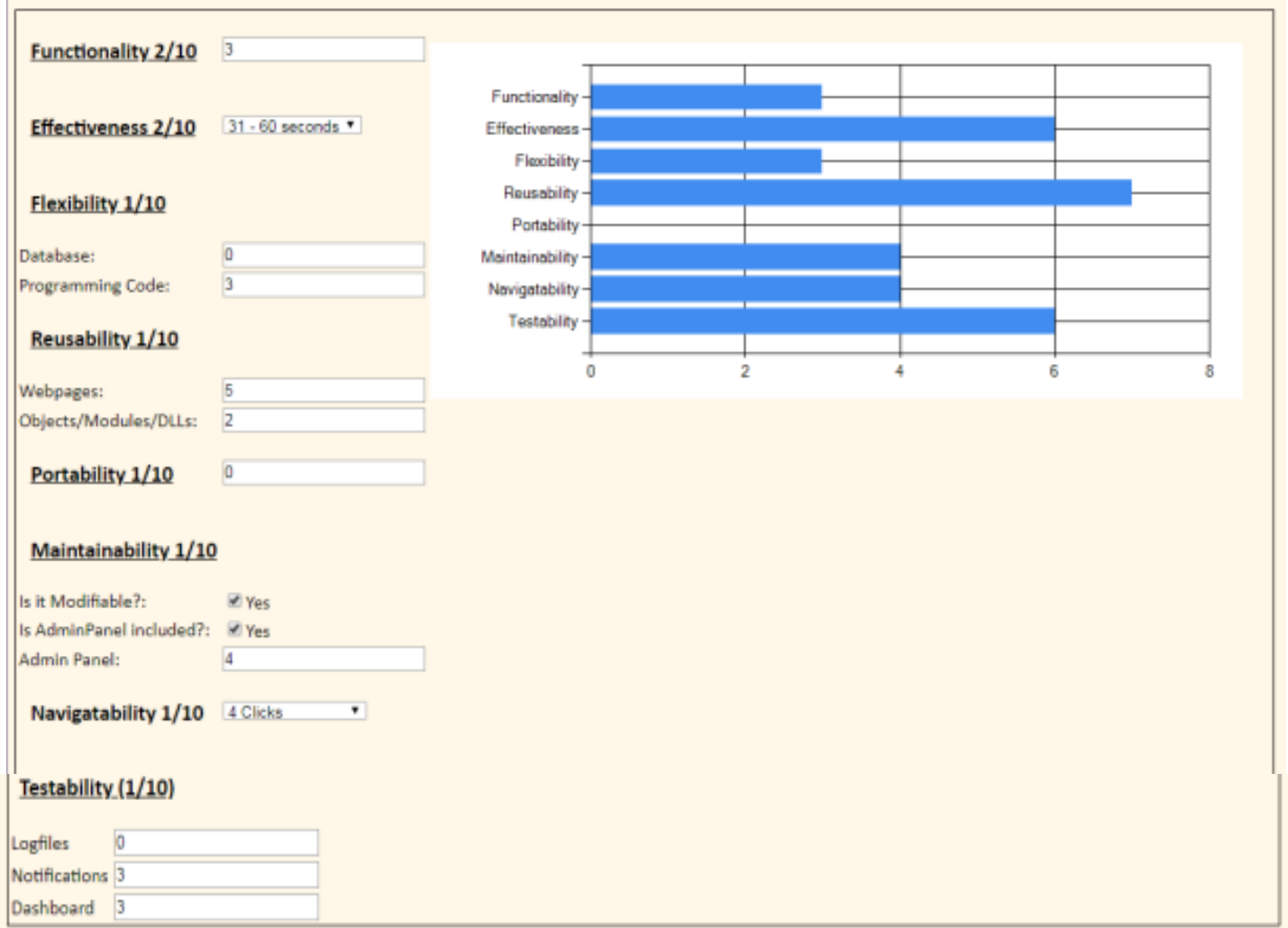

Fig. 1: Organization A-system side

\section{Instructor Side}

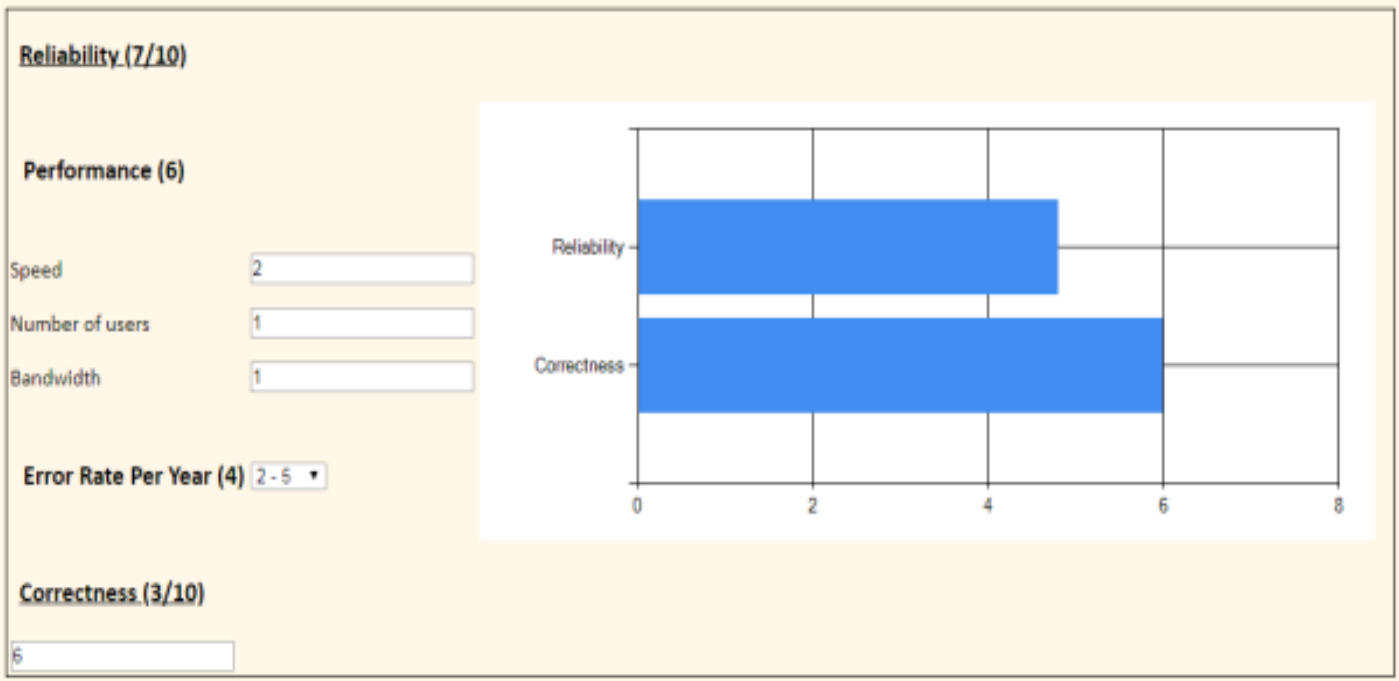

Fig. 2: Organization A-instructor side

has more than twenty different specialties over an area of $4000 \mathrm{~m}^{2}$. They have a respectable E-learning software which supports voice messages (Fig. 1).

Organization A scored good grades for reusability. We hope that they improve their portability in the future (Fig. 2).
Organization A scored good grades for correctness mainly due to the efficient proofreading techniques implemented. Reliability is acceptable (Fig. 3).

Organization A has excellent learnability. Usability was acceptable and could be better if documentation is included (Fig. 4). 


\section{Student Side}

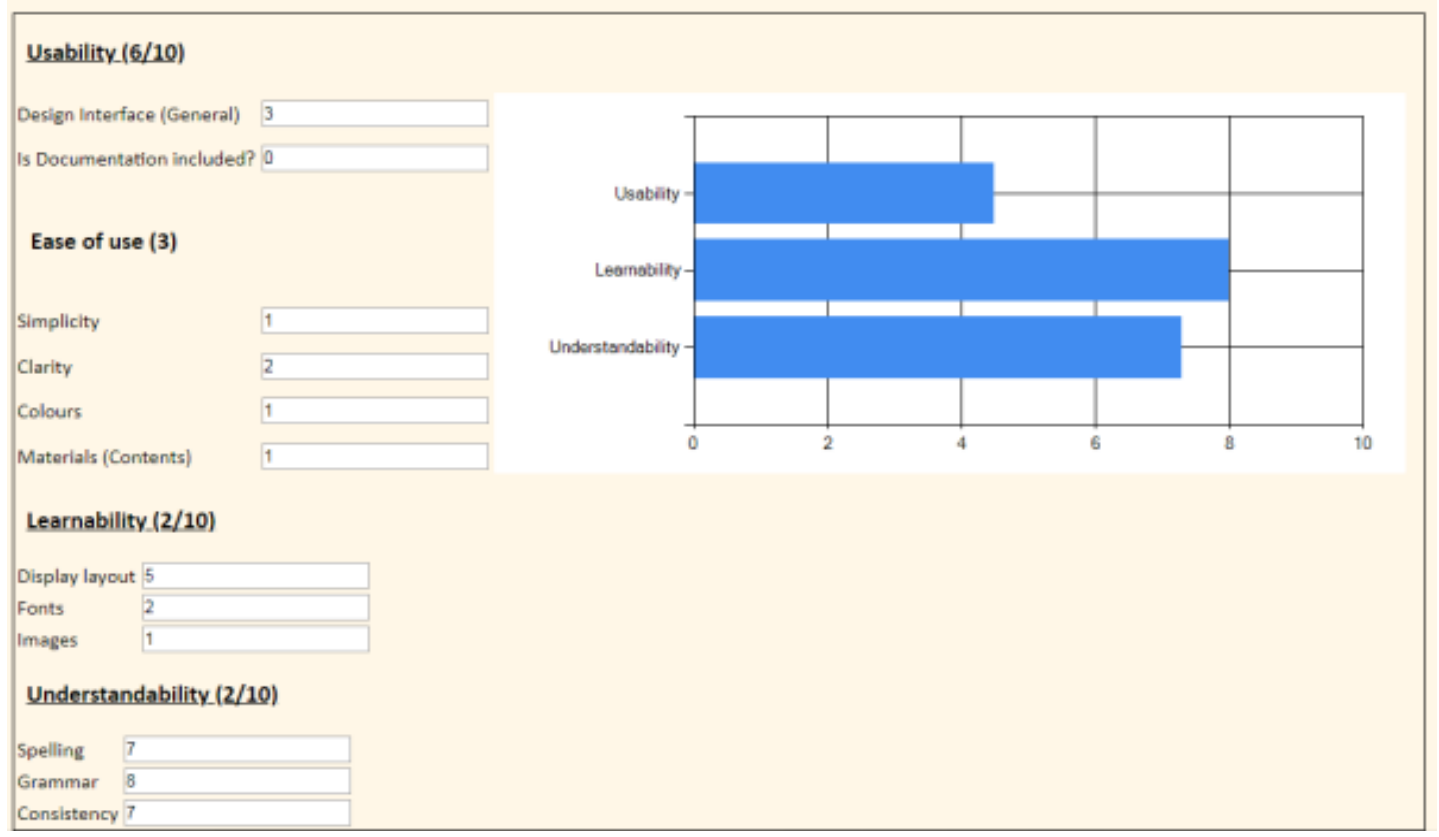

Fig. 3: Organization A-student side

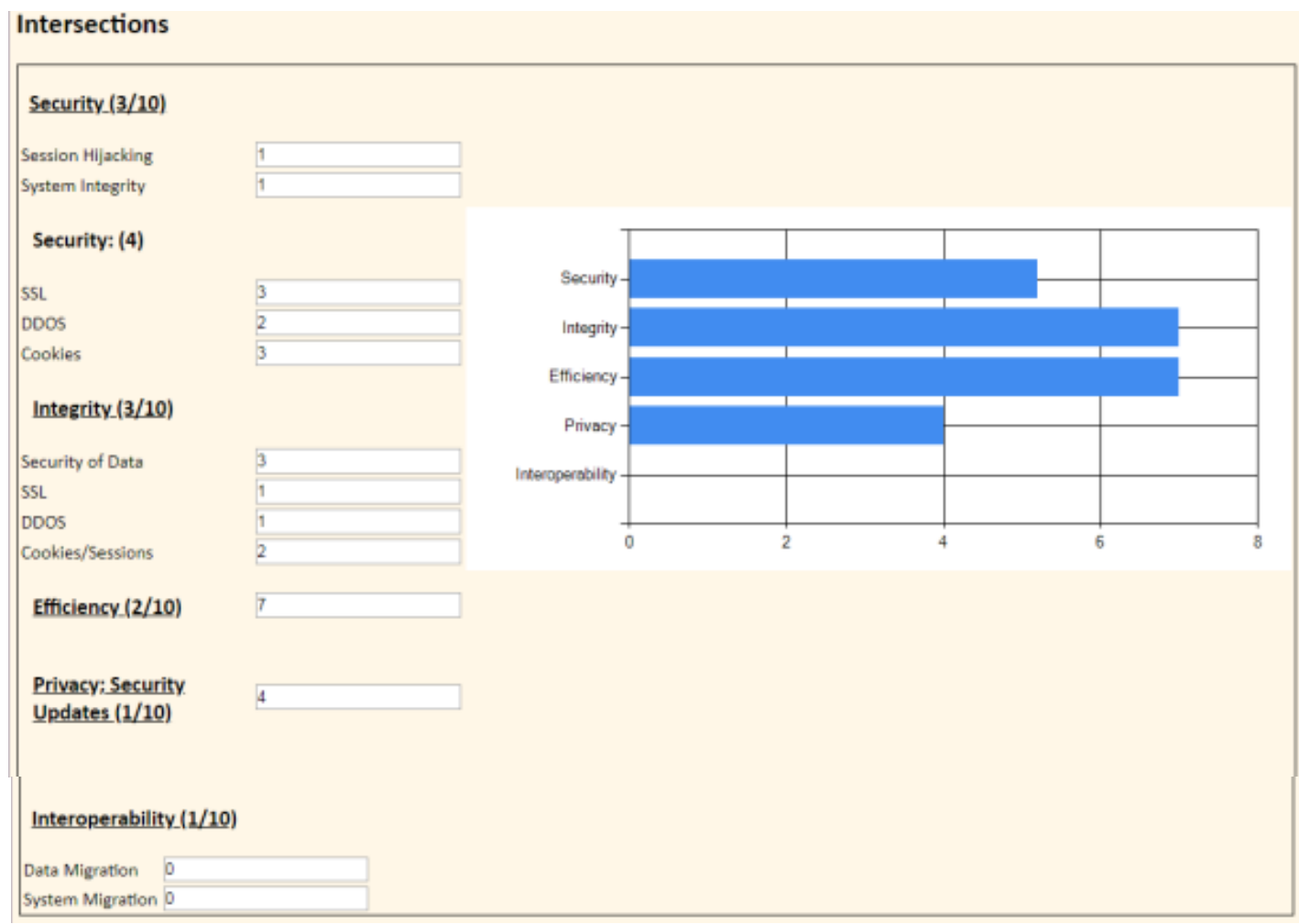

Fig. 4: Organization A-intersections side

Organization A scored good grades for integrity and efficiency with acceptable security and privacy grades (Fig. 5).

Looking at organization A, we notice acceptable results for the system, student, instructor and intersections side. A few efforts are needed over the intersections and student side.

Organization B: Organization B is an undergraduate and postgraduate institution that provides diploma, 


\section{Final Result}

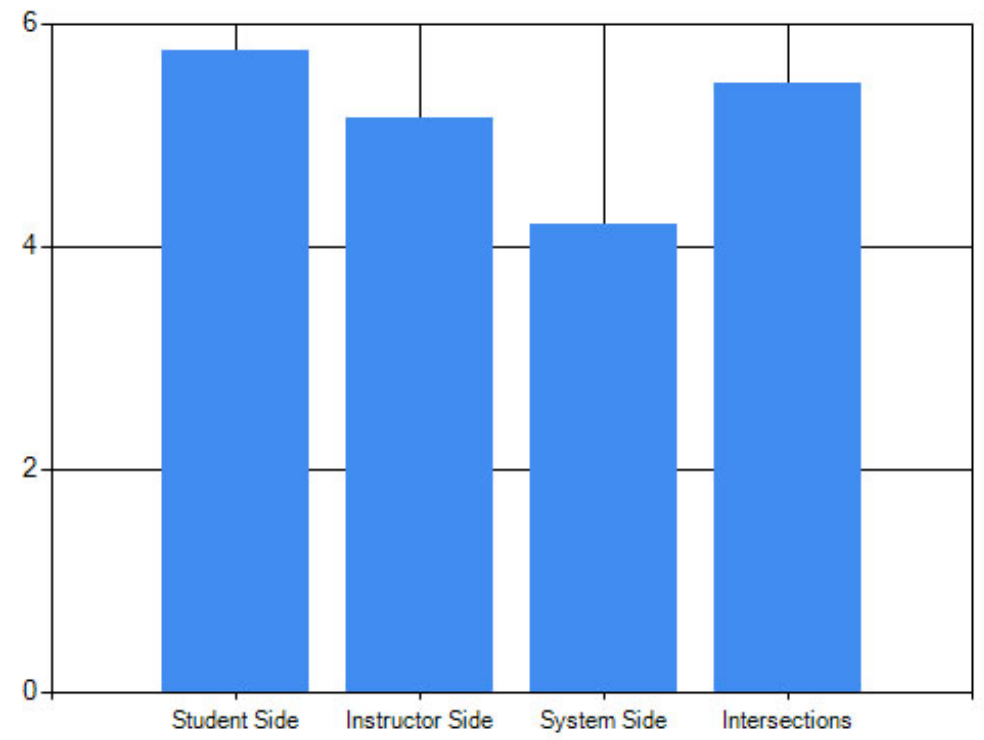

Fig. 5: Organization A

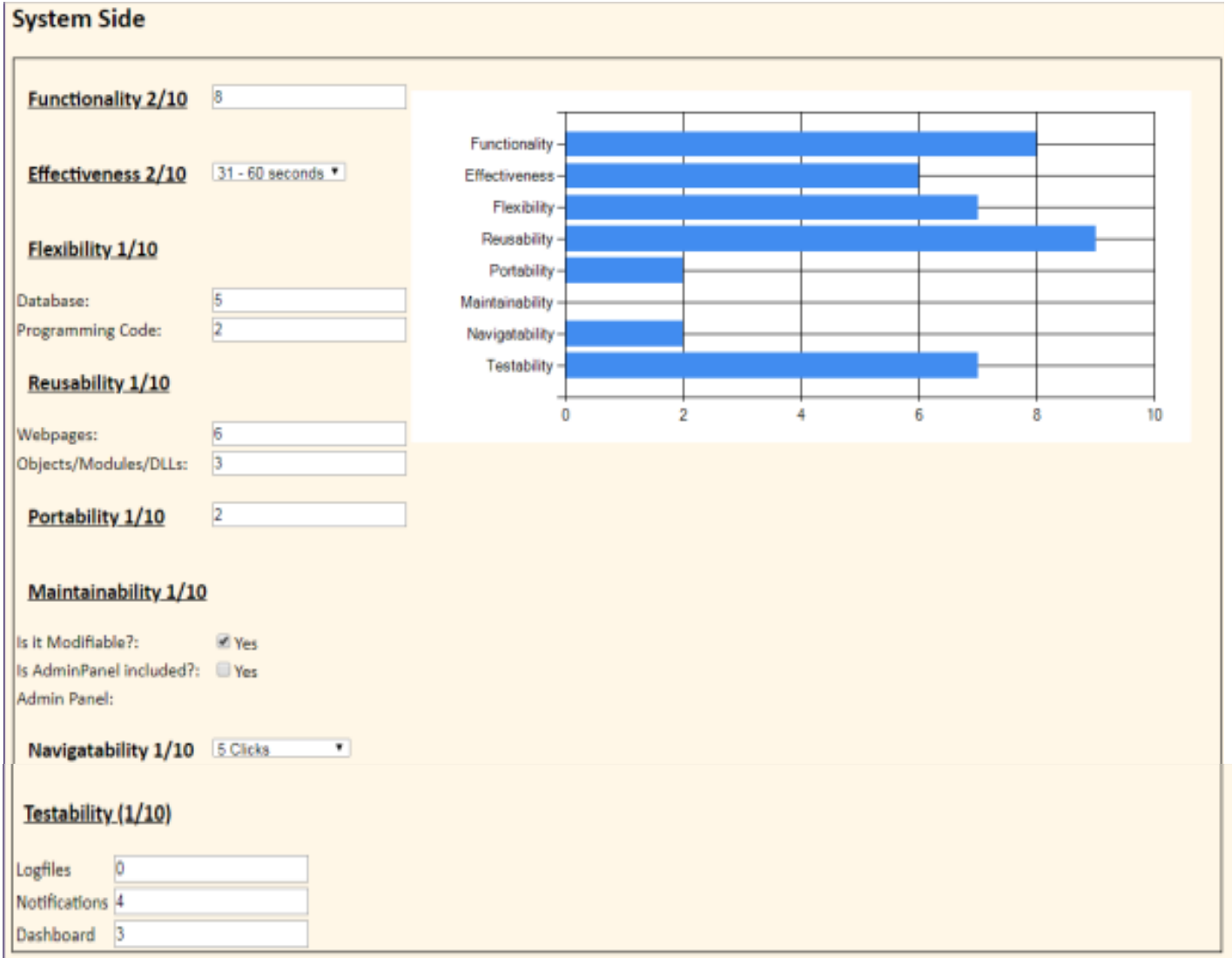

Fig. 6: Organization B-system side

bachelor, masters and doctorate degrees for remote students. It has more than ten different specialties. They have remarkable E-learning software over the internet (Fig. 6). 


\section{Instructor Side}

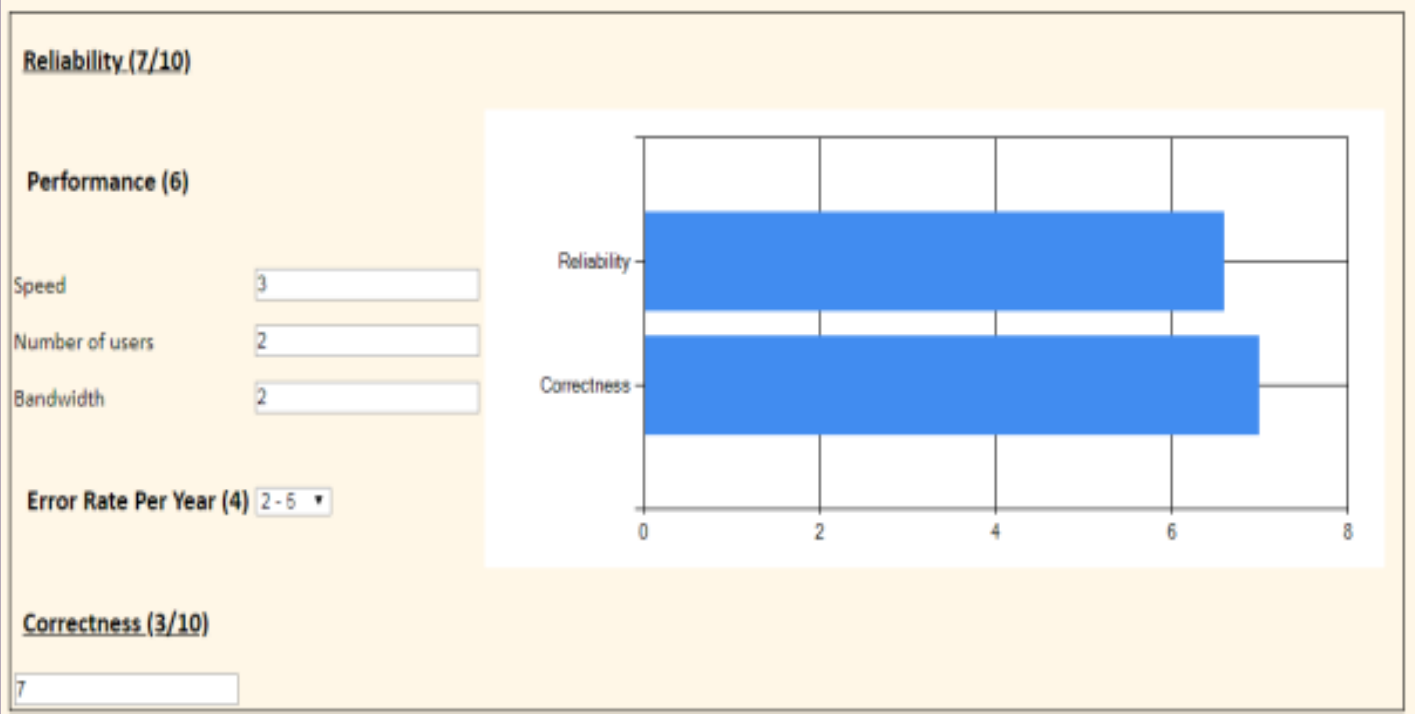

Fig. 7: Organization B-instructor side

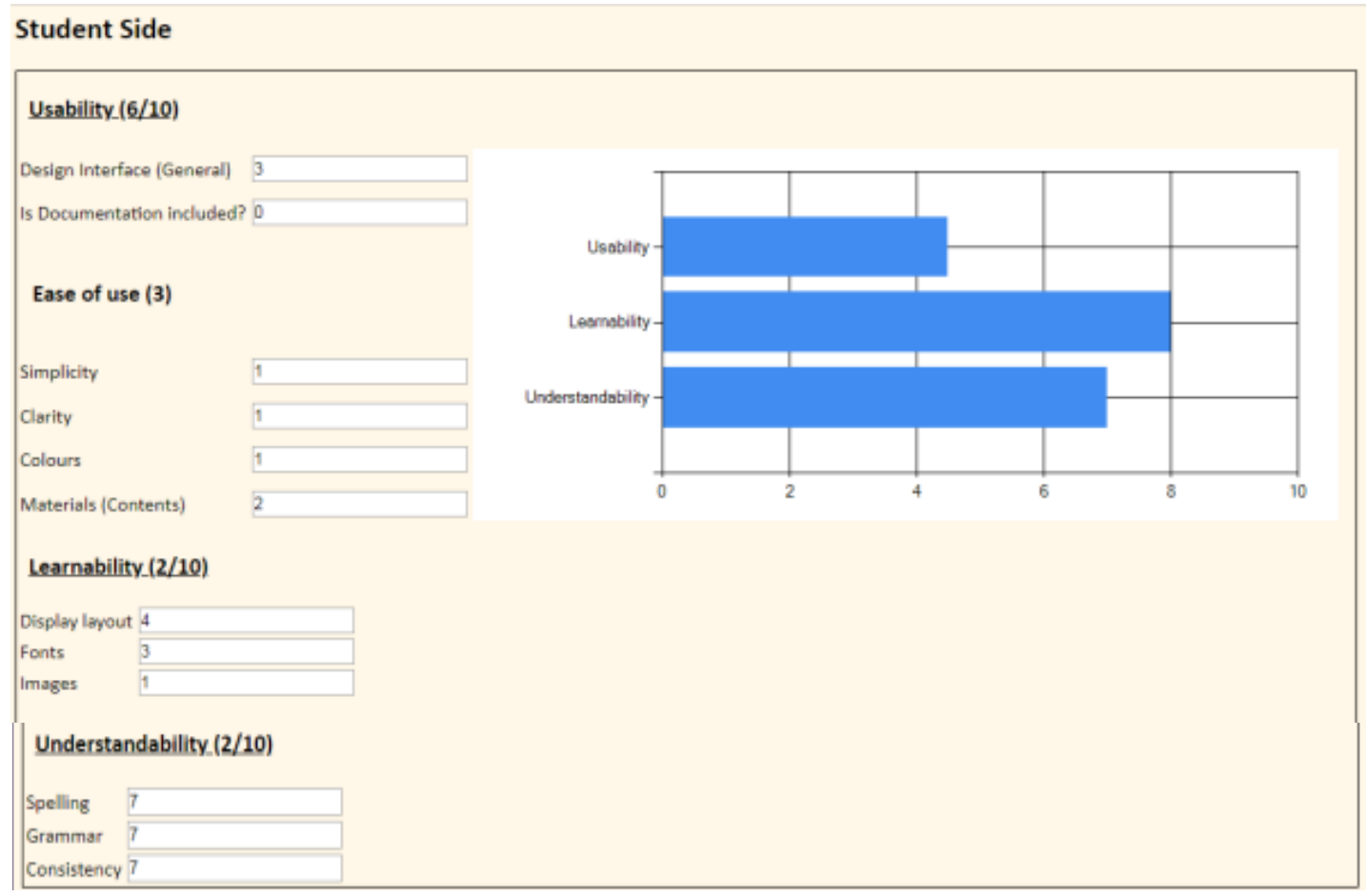

Fig. 8: Organization B-student side

Organization B scored excellent grades for reusability and functionality (Fig. 7).

Organization B scored good grades for correctness and reliability mainly due to the speed in performance and less error rate (Fig. 8).

Organization B has excellent learnability and good understandability (Fig. 9).

Organization B scored good grades for privacy mainly due to the timely security updates (Fig. 10).
Looking at organization $\mathrm{B}$, we notice good results for the instructor side with acceptable results for the other sides. The high performance and less error rate contributed much to the instructor side.

Organization C: Organization $\mathrm{C}$ is an international school that follows British curriculum for secondary school students. It has two branches and more than thirty classrooms. They have respectable e-learning software featuring live boards (Fig. 11). 
Res. J. Appl. Sci. Eng. Technol., 16(1): 30-42, 2019

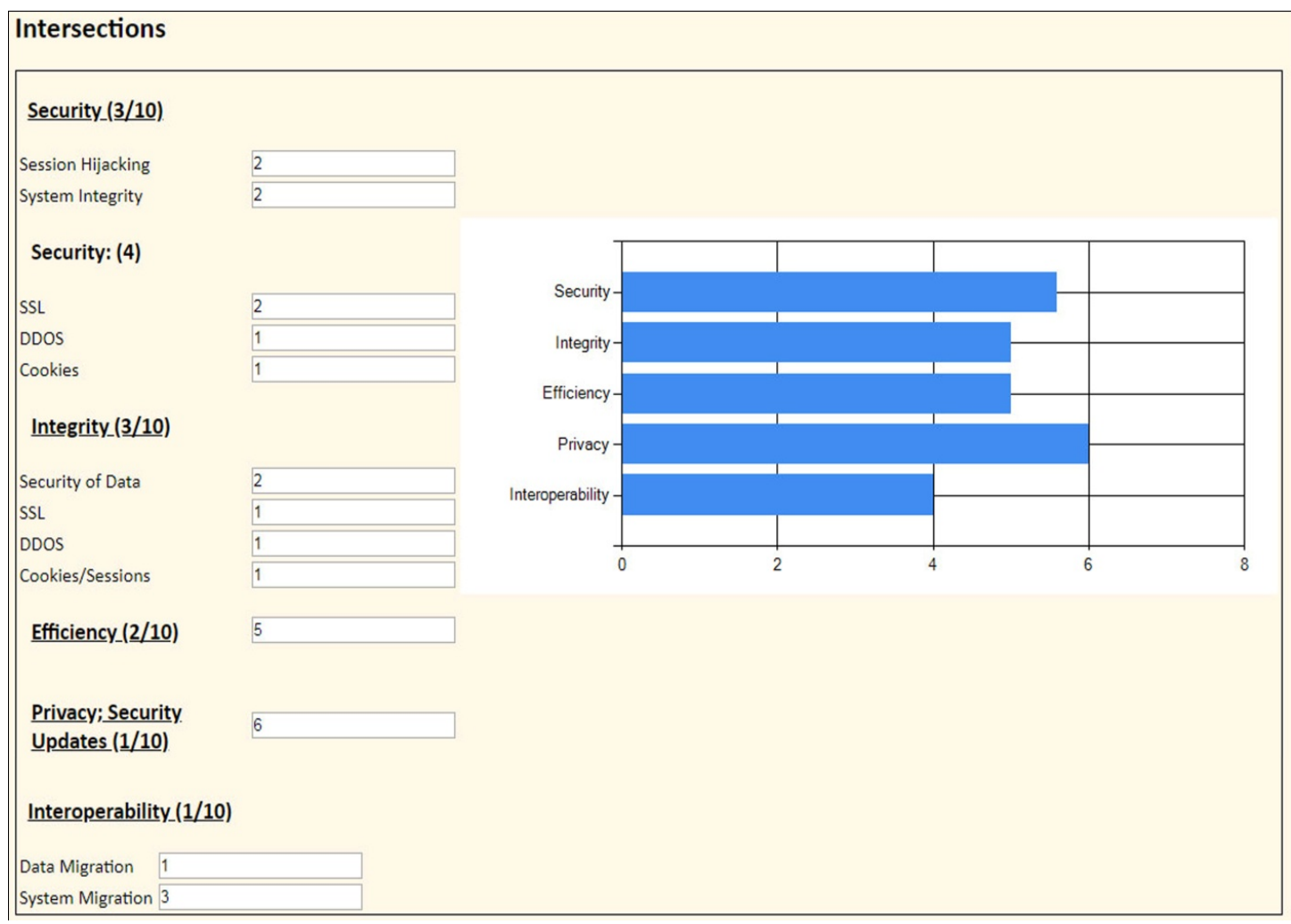

Fig. 9: Organization B-intersections side

\section{inal Result}

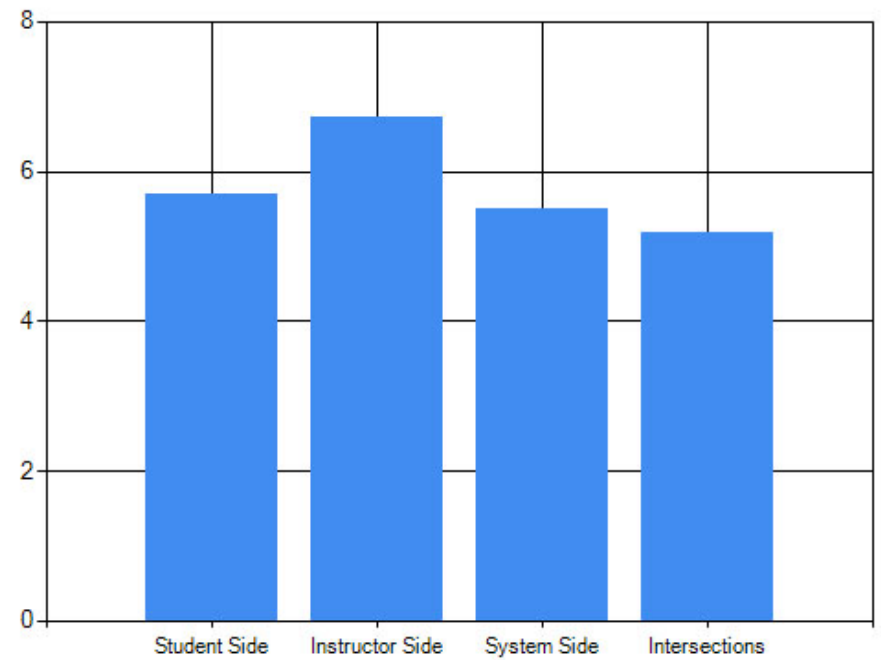

Fig. 10: Organization B

Organization C scored marked excellent grade for effectiveness with functionality, flexibility and reusability (Fig. 12).

Organization $\mathrm{C}$ scored excellent grades for correctness mainly due to the efficient proofreading and verification techniques implemented. Reliability is good mainly due to the high performance (Fig. 13).
Organization $\mathrm{C}$ has excellent usability, learnability and understandability grades. This was mainly contributed by the marked user interface, simple ease of use and excellent user experience (Fig. 14).

Organization $\mathrm{C}$ scored excellent grades for all intersections design factors except for interoperability. 


\section{System Side}

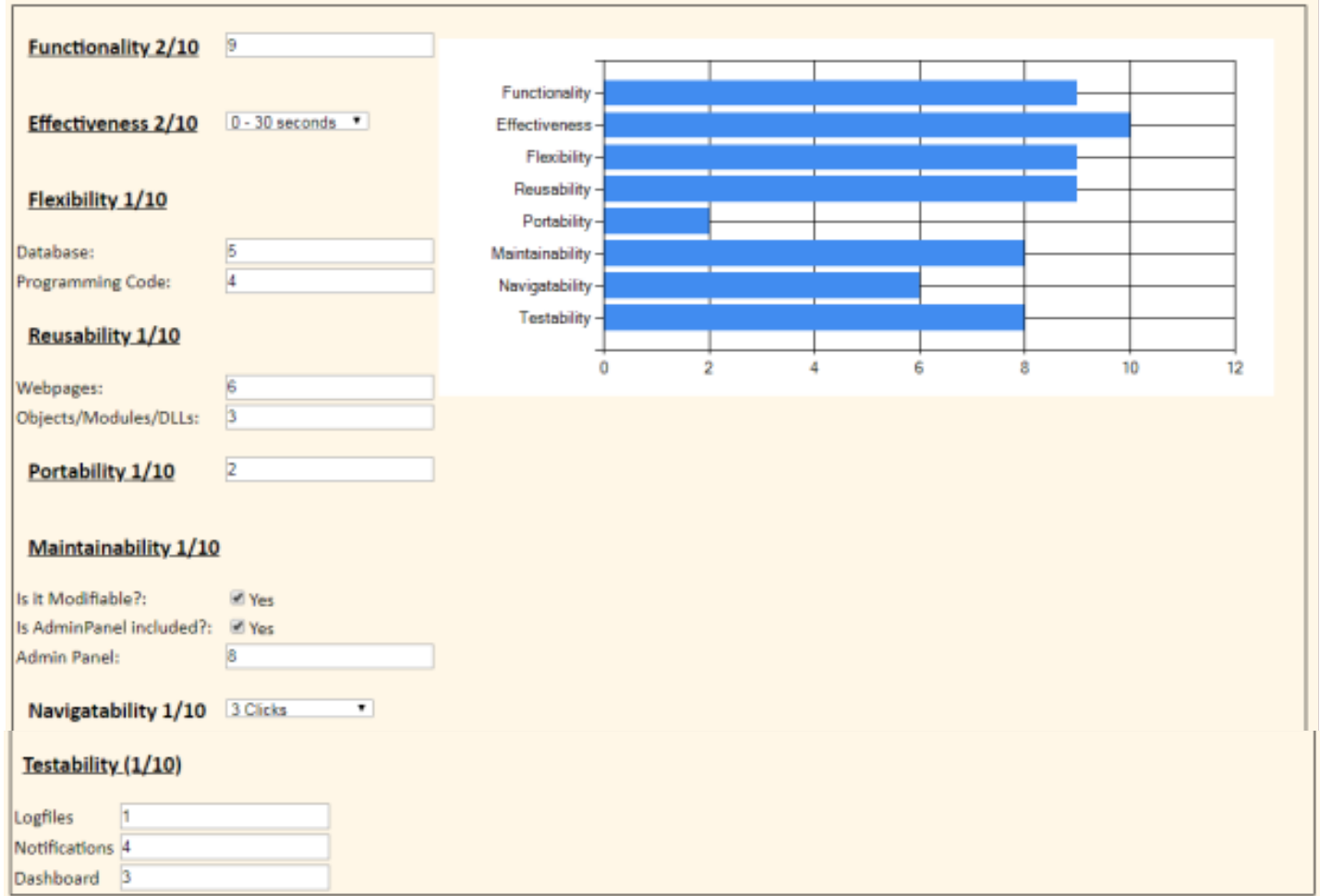

Fig. 11: Organization C-system side

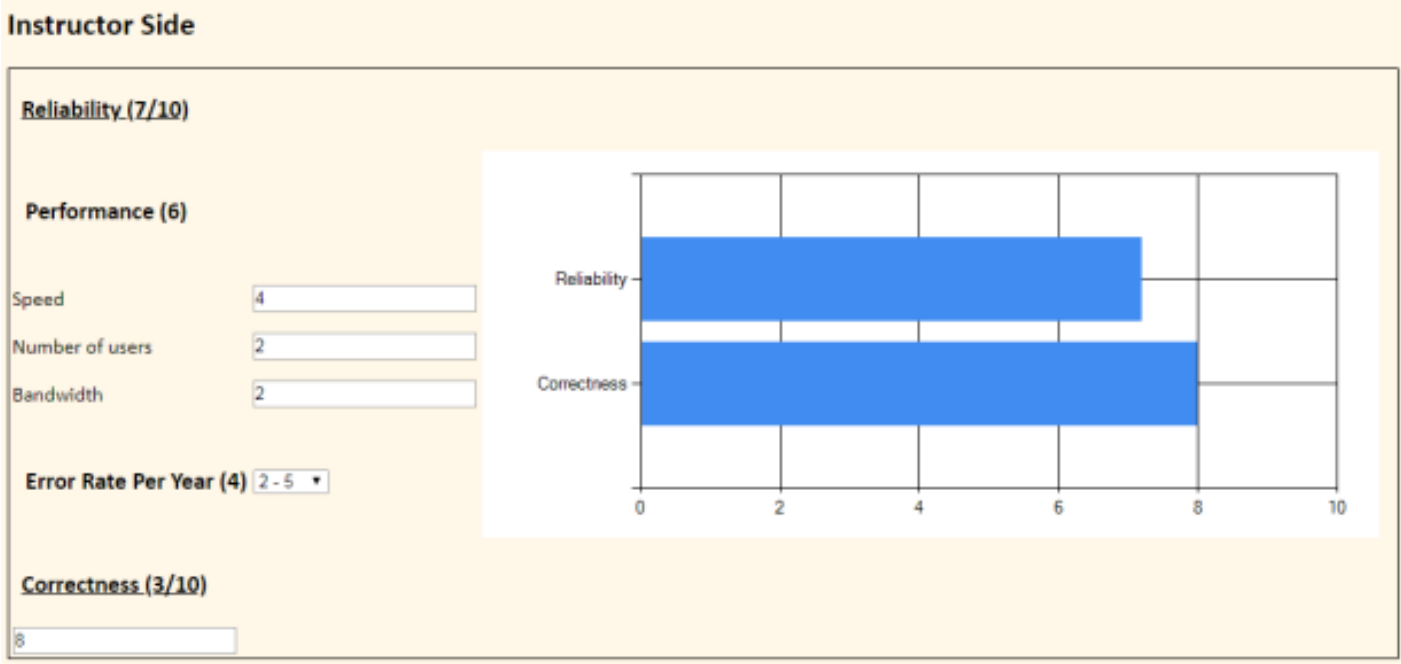

Fig. 12: Organization C-instructor side

Looking at organization C (Fig. 15), we notice marvelous results for the system, student and intersections side.

\section{THE RESULT OF IMPLEMENTING SISM MODEL}

The results of implementing SISM model were accurate and promising. As shown in Fig. 16, comparing the three results, organization $\mathrm{C}$ has the highest overall score. Second is organization B which has good instructor side. Third is organization A with acceptable results. The evaluation results proved the essence of applying the SISM model to aid decision making and software rating. Including the latest measures needed to evaluate latest technologies is essential. 


\section{Student Side}

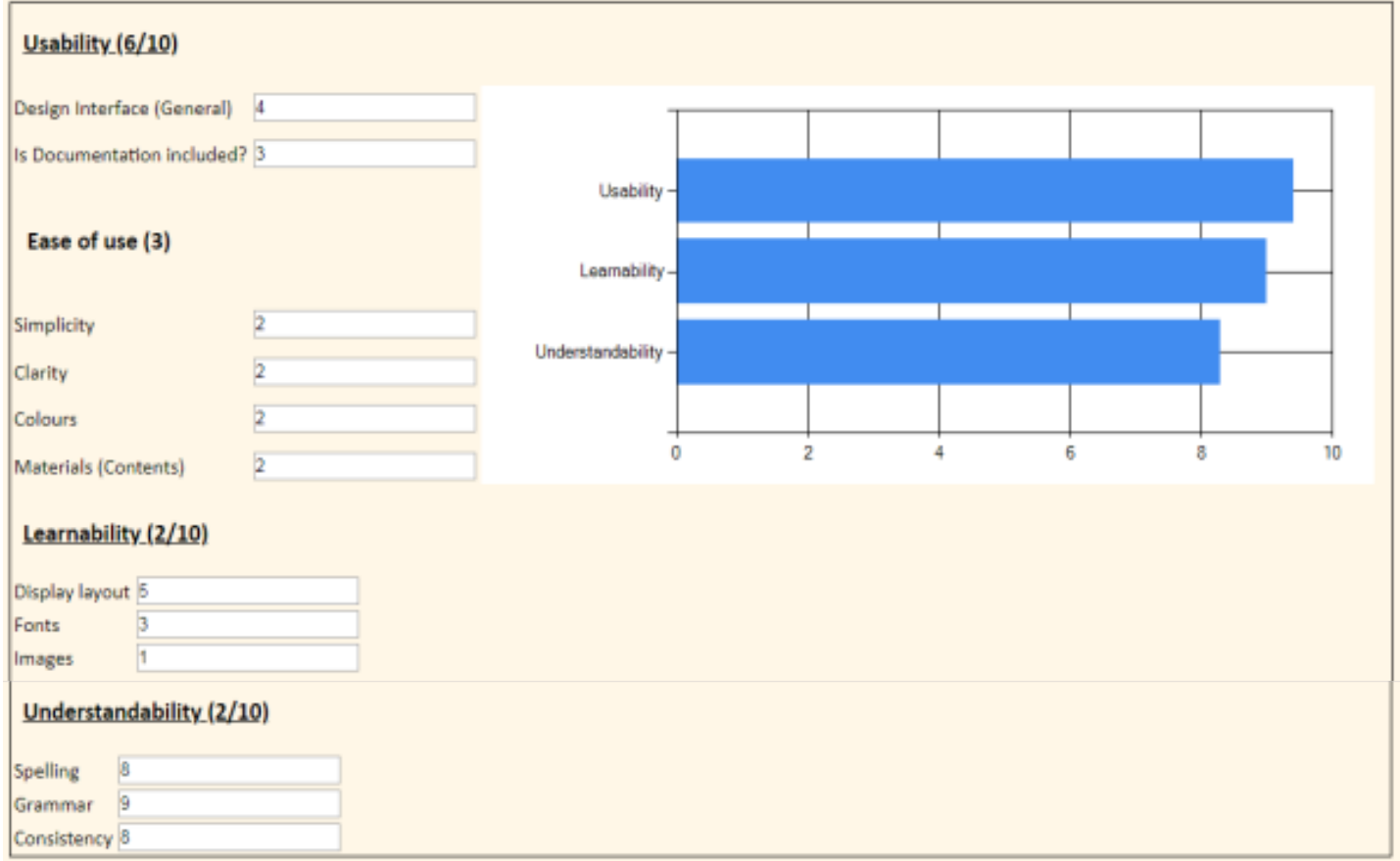

Fig. 13: Organization C-Student Side

\section{Intersections}

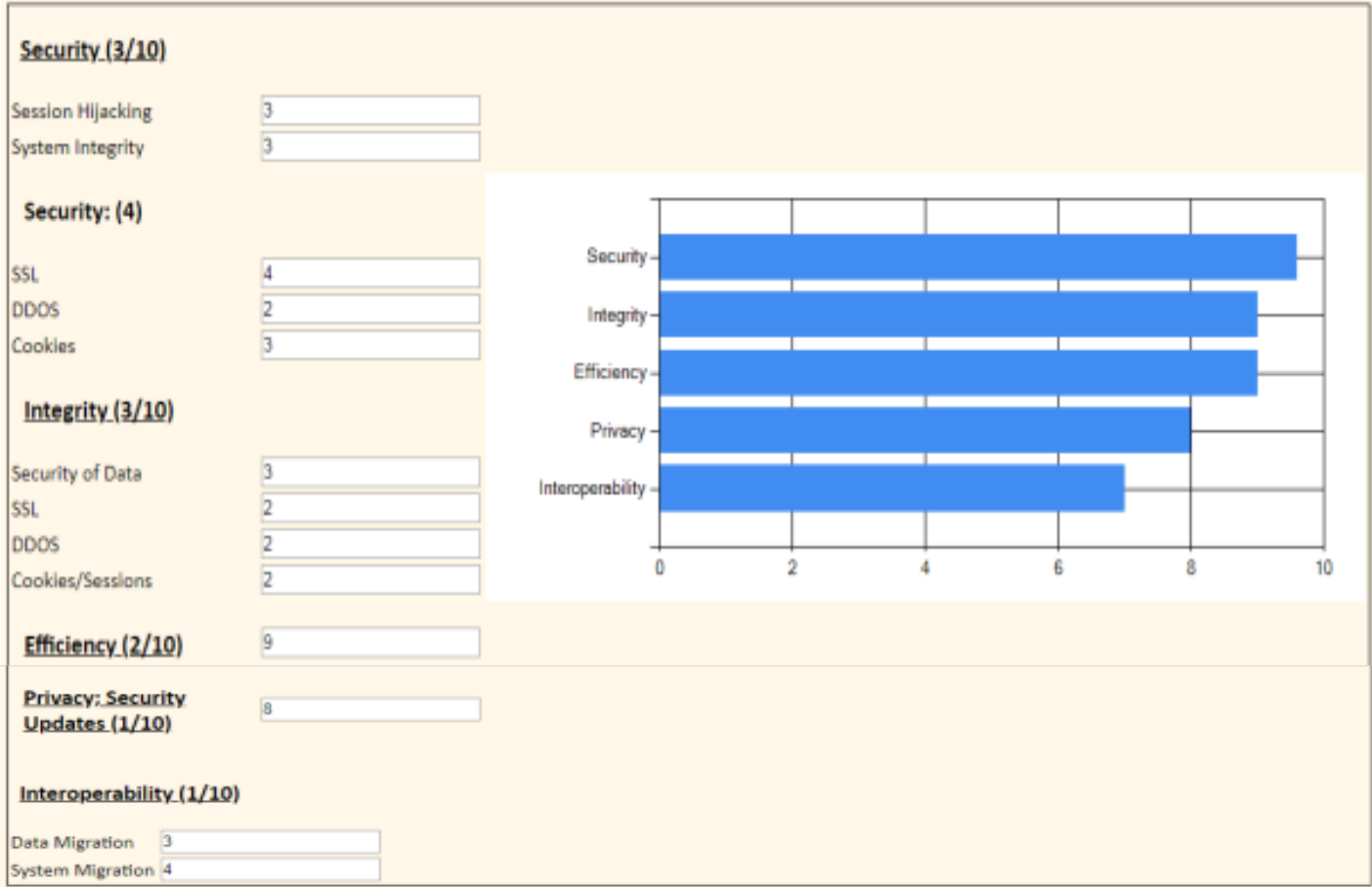

Fig. 14: Organization C-Intersections Side

\section{CONCLUSION}

The software quality model implementation is a complicated job because the needs and requirements are different from model to another. There isn't a single technique or criteria to evaluate E-learning application. The means of quality are different from one perspective to another; therefore, it depends on its task too. To 
Res. J. Appl. Sci. Eng. Technol., 16(1): 30-42, 2019

\section{Final Result}

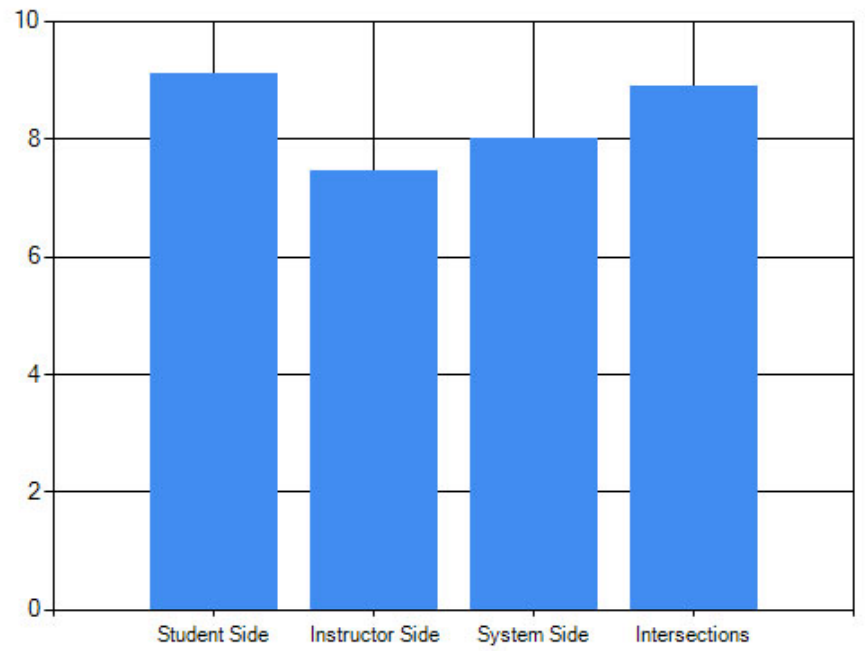

Fig. 15: Organization C

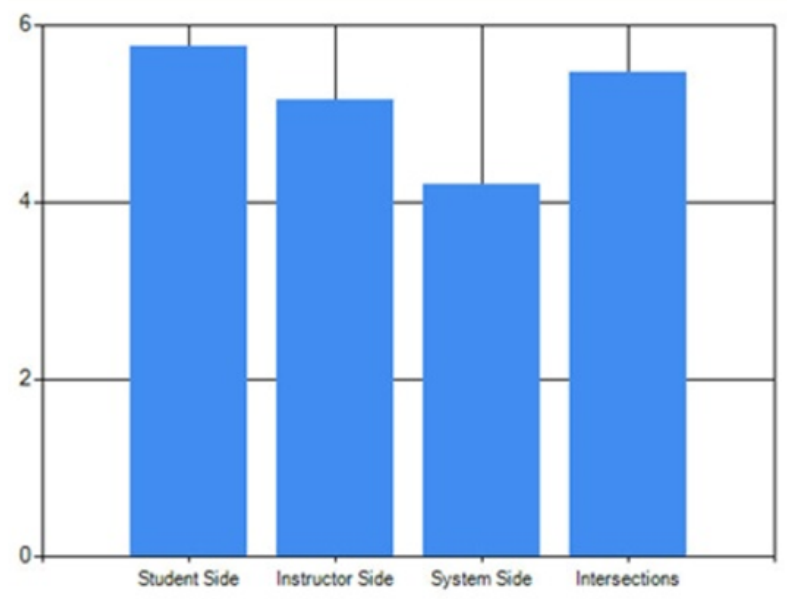

(a) Organization

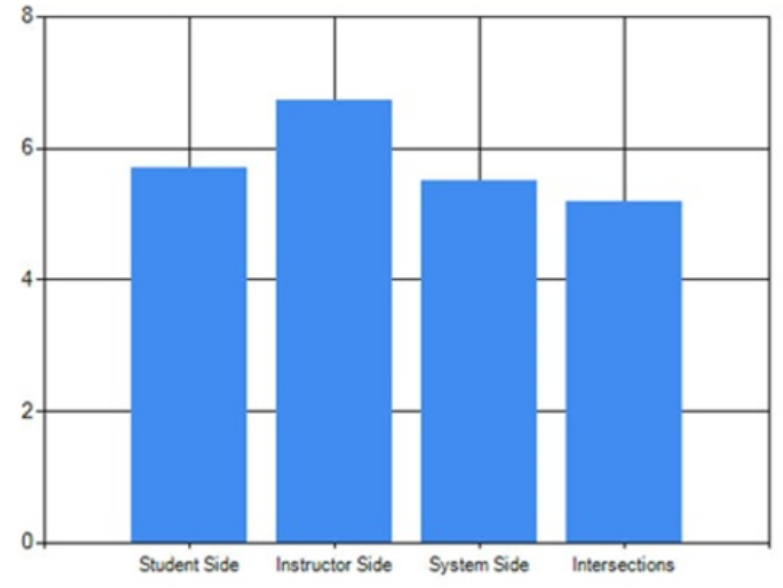

(b) Organization

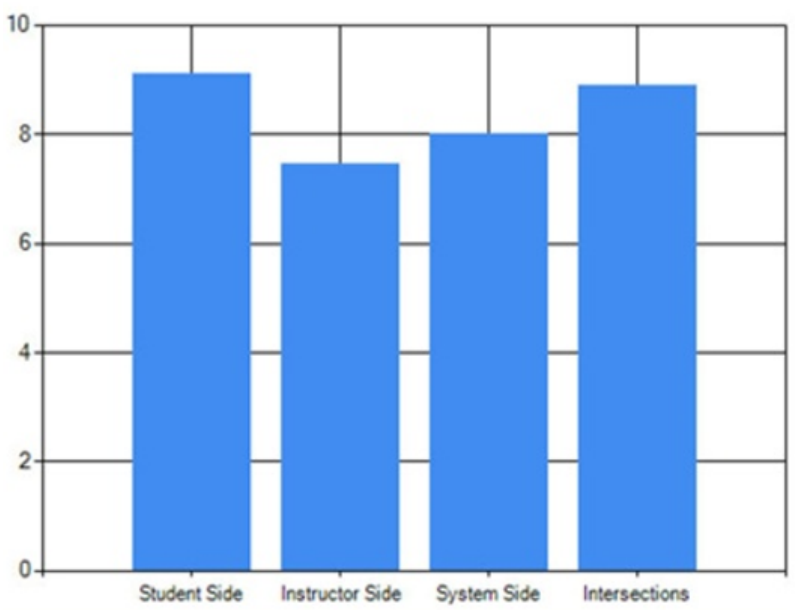

(c) Organization

Fig. 16: Comparative view 
achieve high quality assurance model is a huge challenge, specifically in terms of competition and admiration of the user.

\section{CONFLICT OF INTEREST}

It should be noted that there is no financial support and there is no competitive interest in this area.

\section{REFERENCES}

Allehaibi, K.H. and N.N. Albaqami, 2017. A unified quality control model for E-learning systems. Int. J. Elect. Comput. Eng. (IJECE), 7(3): 1355-1366.

Amin, F.M. and N.K. Salih, 2017. New model to achieve software quality assurance in E-learning application. Int. J. Comput. Sci. Issues (IJCSI), 14(3): 65.

Andrian, R., B. Hendradjaaya and W.D. Sunindyo, 2016. Software assessment model using metrics products for e-Government in the G2B model. Proceeding of the 4th International Conference on Information and Communication Technology (ICoICT), 2016.

April, A. and C.Y. Laporte, 2018. Software Quality Assurance. John Wiley and Sons.

Djouab, R. and M. Bari, 2016. An ISO 9126 based quality model for the e-learning systems. Int. J. Inform. Edu. Technol., 6(5): 370.

Hammad, R., M. Odeh and Z. Khan, 2015. Towards a model-based approach to evaluate the effectiveness of e-learning. Proceeding of the 9th European Conference on IS Management and Evaluation ECIME.

Kim, M., 2016. A quality model for evaluating iot applications. Int. J. Comput. Elect. Eng., 8(1): 66.

Koka, A., 2015. Software quality assurance in scrum projects: A case study of development processes among scrum teams in South Africa. Cape Peninsula University of Technology.

Jiménez Iglesias, L., C. Aguilar Paredes, L. Sánchez Gómez and M. PérezMontoro Gutiérrez, 2018. User experience and the media: The three-click rule on newspaper websites for smartphones. Rev. Latina de Comuni. Soc., 73: 595-613.
Lakshmanan, L.V.S., N. Leone, R. Ross and V.S. Subrahmanian, 1997. ProbView: A flexible probabilistic database system. ACM Trans. Database Syst., 22(3): 419-469.

Levandoski, J.J., A. et al. (2013). "Flexible and extensible preference evaluation in database systems." ACM Trans. Database Syst. 38(3): 1-43.

Mateen, Q. and M. Sirshar, 2015. Software quality assurance in internet of things. Int. J. Comput. Appl., 109(9): 16-24.

Miguel, J.P., D. Mauricio and G. Rodríguez, 2014. A review of software quality models for the evaluation of software products. Int. J. Software Eng. Appli. (IJSEA), 5(6).

Mosa, A., M. Naz'ri bin Mahrin and R. Ibrrahim, 2016. Technological aspects of e-learning readiness in higher education: A review of the literature. Comput. Inform. Sci., 9(1): 113.

Pausch, R., M. Conway and R. Deline, 1992. Lessons learned from SUIT, the simple user interface toolkit. ACM Trans. Inf. Syst., 10(4): 320-344.

Preece, J., et al., 2015. Interaction Design: Beyond Human-Computer Interaction. John Wiley and Sons.

Rohayani, A.H., Kumiabudi and Sharipuddin, 2015. A literature review: Readiness factors to measuring elearning readiness in higher education. Procedia Comput. Sci., 59: 230-234.

Sons, J.W., 2002. Interaction Design.

Storch, A., R. Laue and V. Gruhn, 2013. Measuring and visualising the quality of models. Proceeding of the IEEE 1st International Workshop on Communicating Business Process and Software Models Quality, Understandability and Maintainability (CPSM).

Traxler, J., 2018. Distance learning-predictions and possibilities. Edu. Sci., 8(1): 35.

Trichkova, E., 2014. ISO 9126 Based quality assessment approach for e-learning system. Inform. Technol. Control, 12(1): 21-29.

Zhang, W. and Y.L. Cheng, 2012. Quality assurance in e-learning: PDPP evaluation model and its application. Int. Rev. Res. Open Distribut. Learn., 13(3): 66-82. 